\title{
ТЕМАТИЧЕСКИЕ ГРУППЫ ИНТЕРНАЦИОНАЛИЗМОВ ФРАНЦУЗСКОГО ПРОИСХОЖДЕНИЯ В АНГЛИЙСКОМ ЯЗЫКЕ
}

\section{THEMATIC GROUPS OF FRENCH INTERNATIONAL LEXICAL UNITS IN ENGLISH}

I. Ilina

Summary: This article deals with French international words in English. International vocabulary is considered to be the lexical units that exist in three or more non-related languages. One of the sources of this kind of vocabulary in various European languages, including English, was French. In linguistics, there are a large number of classifications of word and one of them is thematic groups. According to the results of our research, the largest group of international words of French origin in English was the group «Human being.»

Keywords: international lexical units, borrowing, French language, English language, thematic groups.

\author{
Ильина Юлия Николаевна \\ К.филол.н., дочент, ФГБОУВО «Удмуртский \\ государственный университет», (г. Ижевск) \\ julianik23@mail.ru
}

Аннотация: В данной статье рассматриваются интернационализмы французского происхождения в английском языке. Интернациональной лексикой принято считать лексические единицы языка, которые существуют в трех и более неблизкородственных языках. Одним из источников такой лексики в разных европейских языках, в том числе английском, стал французский язык. В языкознании существует большое количество классификаций групп слов, объединенных каким-либо признаком, и одной из них являются тематические группы. По результатам нашего исследования, самой многочисленной группой интернационализмов французского происхождения в английском языке стала группа «Человек».

Ключевые слова: интернационализмы, заимствования, французский язык, английский язык, тематические группы.

нения которых можно установить интернациональные слова и степень их международности. Впервые группа «контрольных языков» была очерчена Американским философским обществом (1887), которое причислило к ним «шесть основных языков, располагаемых в порядке их значимости и распространения» на тот период: английский, французский, немецкий, испанский, итальянский и русский [3; с. 40]. Интернациональная лексика существует как составная часть конкретных национальных языков и занимает определенное место в их системе.

Говоря об источниках возникновения интернациональной лексики в разных языках, нельзя не упомянуть классические языки (греческий, латинский), а также романские, такие, как итальянский и французский, а на современном этапе, несомненно, английский [7; с. 97]. Однако не стоит забывать, что большая часть лексического фонда английского языка латинского или французского происхождения. В мировом интернациональном фонде исследователи насчитывают свыше 2000 слов французского происхождения. В данной статье изучается лексика французского происхождения в английском языке, при этом рассматриваемые лексические единицы являются интернационализмами, т.е. существуют и в других языках. Общее количество языковых единиц составило около 1 тыс. слов.

Слова в языке живут не изолированно, а вступают в разнообразные отношения с другими словами, образуя определенную систему. При изучении смысловых связей 
в системе языка исследователи обращают внимание на существование связей явлений и предметов действительности. Вопрос об изучении словарного состава ставится впервые в истории языкознания в начале XX в. Многообразие смысловых связей между словами обусловило появление в языкознании большого количества классификаций типов групп и систем слов: предметные (тематические), терминологические, этимологические, понятийные (семантические), лексико-семантические и др.) [8; с. 17, 132-137]. Громоздкость и необозримость лексико-семантической системы в целом побуждают исследователей ограничиваться частными системами в ее составе, выделяя различного рода лексико-семантические группы, классы, поля.

Слова, объединяющиеся по сходству значения, составляют лексико-семантические группы, а устанавливающие ассоциации по смежности значения, составляют тематические группы [4; с. 140]. Объединение слов в одну тематическую (или предметную) группу происходит в силу сходства или общности функций обозначаемых словами предметов и процессов в одном или разных языках, критерием объединения выступает номинативная сторона слов [8; с. 133]. Такие группы могут включать в себя слова разных частей речи по теме описания.

Распределение слов по различным группам является одним из методов сопоставительного изучения лексики. C конца XIX в. и в течение XX в. европейские языковеды (Й. Трир, В. Порциг, Ф. Дорнзайф, Р. Халлиг, В. фон Вартбург, Г. Маторэ) и отечественные ученые (А.А. Потебня, М.М. Покровский, В.В. Виноградов, Ю.Н. Караулов, Р.Ш. Насибуллин, Ю.С. Степанов) продуктивно работали в этой области. Многие исследователи, изучающие заимствования, также придают большое значение классификации по понятийным группам и предлагают свои варианты. Выделение таких групп позволяет выявить степень взаимодействия народов в разных областях.

Выделив номинативную сторону слов как критерий их объединения и опираясь на данные разных исследований и собственный анализ языкового материала, мы распределили изучаемые нами интернационализмы французского происхождения в английском языке по следующим тематическим группам:

А. Вселенная;

Б. Человек:

1. Человек как физическое существо;

2. Душа и интеллект;

3. Человек как социальное существо;

В. Человек и Вселенная:

1. Априори;

2. Наука.

Языковой материал, представленный в данном параграфе, является лексикой французского происхождения высокой степени интернационализации, и базируется на «Многоязычном словаре» [6; с. 77-93]. Распределение проводилось на синхронном уровне современного состояния изучаемой лексики.

Каждая тематическая группа в свою очередь делится на несколько подгрупп. При распределении интернационализмов по группам мы столкнулись с несколькими трудностями: во-первых, большинство рассматриваемых слов в английском языке являются полисемантичными, т. е. имеют несколько значений, относящихся к разным сферам и областям жизни. Известно, что многозначные слова могут одновременно включаться в ряд лексико-семантических и тематических групп [4; с. 141]. Для определения слов в какую-нибудь тематическую группу мы руководствовались основным значением, зафиксированным в современных словарях. В случае расхождения распределения значений в разных словарях предпочтение отдавалось значениям, данным в англоязычных словарях.

Анализ французских интернационализмов в английском языке с учетом тематических групп позволяет сделать следующие наблюдения и выводы.

Количество интернационализмов французского происхождения в английском языке распределилось по группам следующим образом: подав ᄀляющее число примеров относятся к группе «Б. Человек» (86\% от всего кор ᄀпуса примеров), далее следует группа «В. Человек и Вселенная» (11\%), и наилменьшее количество слов входит в группу «А. Вселенная» (3\%). Рассмотрим распределение лексических единиц по подгруппам внутри каждой группы.

Самой многочисленной по составу группой является группа «Б. Человек», так как деятельность человека многопланова и требует разнообразных лексических средств для ее описания и характеристики, что объясняет и дробный характер классификации данной группы на три подгруппы («Человек как физическое существо», «Душа и интеллект» и «Человек как социальное существо») и большое количество разделов в каждой из них. Наиболее широко представлена подгруппа «Человек - социальное существо» (61\% от всего корпуса примеров), что объясняется тем фактом, что жизнь человека не мыслима вне общества. Далее следует группа «Человек как физическое существо» (15\%), и на третьем месте по численности слов находится «Душа и интеллект» (10\%).

Внутри подгруппы «Человек - социальное существо» по значимости выделяются некоторые разделы. Наибольшее количество французских интернационализмов в английском языке (14\%) относятся к разделу «Страна, государство, общество» (например, assembly, career, organization, parliament, premier). Этот факт объясняется тем, 
что Франция всегда играла активную роль на мировой политической арене, и многие державы перенимали способы французского политического устройства, а для обозначения новых реалий заимствовали иноязычные слова. Что касается французского влияния на английский язык, Нормандское завоевание, Столетняя война, и, как следствие, тесное взаимодействие двух народов и языков на протяжении столетий, привели к заимствованию огромного количества слов, связанных с политическим устройством государства. Наиболее обширны группы слов, объединяющие различные должности и профессии (engineer, journalist, mayor, minister, secretary) и лексику, характеризующую общественную жизнь (diplomatic, partisan, picket, social, tribune).

Французское искусство и литература играли передовую роль в мире во времена эпохи Возрождения и позже, что отразилось на словарном составе многих языков, который пополнился французскими словами из этой области жизни: actor, bust, etude, nuance, paysage (9\%) (раздел «Художественная литература и искусство»).

Следующий раздел лексики «Национальная оборона» объединяет слова, обозначающие понятия, связанные с войной и военными действиями, оружием, воинскими званиями и т. д. (army, bomb, lieutenant, mobilization, pistol) (7\%). Большое количество слов французского происхождения военной тематики в мировых языках связано с тем фактом, что исторически Франция была крупной и могущественной военной державой, участвующей во многих военных конфликтах разных эпох.

В разделе «Жилье» представлены слова, обозначающие виды помещений, построек, предметы мебели и утварь (bureau, cabinet, drape, flagon, terrace), этот пласт лексики составил 7\% от общего количества примеров. В английском языке функционируют многочисленные лексические единицы французского происхождения из данной категории. Даже наиболее важные по значимости в любом жилом помещении предметы, известные человечеству с давних пор, и обозначаемые во многих языках исконными словами, обозначаются в английском языке при помощи французских заимствований, это такие слова, как bench «скамья», chair «стул», table «стол» и др. В подобных случаях французские слова появлялись в английском языке одновременно с появлением привнесенных завоевателями предметов, либо вытесняли уже существующие исконные слова. Английский язык испытывал сильнейшее влияние французского языка на протяжении довольно длительного периода, и это происходило до и во время становления английского языка как национального. На другие же языки французский язык оказывал влияние в то время, когда они уже достаточно сформировались для того, чтобы не замещать заимствованными словами слова исконные. В их случаях происходило заимствование только тех слов, которые обозна- чали новые для этих языков предметы, характерные для французского быта (ср. рус. буфет, комод, паркет).

Раздел «Взаимоотношения в обществе» представляет собой лексические единицы, выражающие разного рода отношения между людьми в обществе, они составили 5\% от всего количества примеров. Это такие слова, как companion, hero, intrigue, personage, solidarity.

Другие разделы не так многочисленны: примерно одинаковое количество слов (по убывающей) представлено в разделах «Транспорт, передвижения» (metro, pedal, transport), «Населенные пункты и учреждения» (alley, farm, region), «Экономика, торговля и денежные отношения» (budget, commerce, rent), «Игры, праздники, развлечения» (adventure, ball, hazard), «Речь»(dialogue, parole, report). Каждый из указанных разделов насчитывает по 2-3\% от всей рассматриваемой лексики. Остальные разделы данной подгруппы насчитывают всего по 1-2\% от всего количества рассматриваемых примеров, все они отражают различные области профессиональной деятельности человека (arbiter, commerce, mine).

Второй по численности подгруппой интернационализмов внутри группы «Б. Человек» является подгруппа «Человек как физическое существо». Данная подгруппа представлена несколькими разделами, самым значительным из них является раздел «Одежда» (5\%), в котором находятся слова, обозначающие предметы одежды, аксессуары и имеющие отношение к моде (blouse, chic, costume, fashion, veil), и это не удивительно, так как общеизвестно, что Франция была и остается законодательницей моды и стиля.

Следующим важным разделом является раздел «Движение, действие», слова из которого составляют 4\% от всей изучаемой лексики французского происхождения. Это такие слова, как advance, gesture, to operate, to turn, shock. Нужно отметить одну особенность данной лексики в английском языке: слова, представленные в этом разделе, например, to advance, to pass, to reform, shock, в английском языке имеют в качестве первого, основного значения действия физического плана, а не только переносное значение, как в других языках, также заимствовавших эти же слова. Например, приведенные выше слова означают соответственно «продвигаться вперед», «проходить мимо», «переделывать», «удар». Для сравнения в русском языке их эквиваленты «авансировать», «пасовать», «реформировать», «шок» имеют переносное значение или абстрактный смысл.

Примерно такое же количество слов входит в раздел «Человеческие потребности», где представлены слова, обозначающие продукты, виды блюд, напитков и т. п. (biscuit, conserve, jelly, menu, sausage). Данный факт также вполне объясним, поскольку французское влияние в 
области гастрономии и приготовления пищи испытали на себе многие европейские народы. Слова, входящие в другие разделы этой подгруппы, единичны (cigarette, grippe, nerve).

Третьей по численности внутри группы «Б. Человек» является подгруппа «Душа и интеллект» (10\%). Эти слова представляют собой разнообразные абстрактные понятия, выражающие чувства, мысли и желания человека. Заимствование такого рода лексики в мировые языки связано с сильным влиянием французских просветителей и философов на мировоззрение образованных людей всего мира. В английском же языке многие из этих слов, например, accord, confusion, interest, serious, surprise и др., появились задолго до эпохи Просвещения, еще в XII-XV вв., когда французский язык играл важную роль во всех сферах, в том числе в сфере образования и науки. Наибольшее количество слов принадлежит в этой подгруппе разделу «Разум, мысль, интересы» (4\%), к ним относятся слова compliment, detail, egoism, intelligence, talent.

Группа «В. Человек и Вселенная» включает в себя две подгруппы - «Априори» (9\%) и «Наука» (2\%). Первая из них имеет несколько разделов, включающих слова, обозначающие различные характеристики объектов (размер, форму, число и т. д.), больше всего слов представлено в разделе «Число, вес, количество» (4\%). Здесь имеются как слова, являющиеся мерой $(\operatorname{gram}(m e)$, kilo, litre) и передающие точное количество чего-либо (million, milliard), так и слова, имеющие обобщающее значение некоторого неопределенного количества (reserve, suite, series).

Подгруппа «Наука» малочисленна (2\%) (materialism, parasite, Romance), что, вероятно, объясняется тем фактом, что научная интернациональная терминология имеет, как правило, латинское или греческое происхождение, слова французского происхождения в научных областях знания встречаются не так часто.

Таким образом, мы видим, что французская интернациональная лексика в принимающих языках представлена во всех подгруппах неравномерно. Данный факт объясняется различной степенью интенсивности французского влияния на разные сферы жизни человека.

Произведенное тематическое распределение изучаемого материала позволило наблюдать широкую семантическую палитру французских интернационализмов. Однако, как уже отмечалось, в данной статье указывалось только основное словарное значение лексических единиц, поскольку слова французского происхождения в английском языке, как правило, полисемантичны.

\section{ЛИТЕРАТУРА}

1. Акуленко В.В. Вопросы интернационализации словарного состава языка. - Харьков: Изд-во Харьковского гос. ун-та, 1972. - 215 с.

2. Акуленко В.В. Существует ли интернациональная лексика? // Вопросы языкознания. - № 3. - М.: Изд-во АН СССР, 1961. - С. 60-69.

3. Аролович А.В. Общее и различное в интернациональной лексике романских языков // Вестник МГу. - Сер. 19. Лингвистика и межкультурная коммуникация. - 2003. - № 2. - С. 38-55.

4. Гак В.Г. Беседы о французском слове: Из сравнительной лексикологии французского и русского языков. - М.: Междунар. отношения, 1966. - 335 с.

5. Головин Б.Н. Введение в языкознание. - 4-е изд., испр. и доп. - М.: Высш. шк., 1983. - 232 с.

6. Зеленина Т.И., Загуляева Б.Ш., Буторина Н.В. Многоязычный словарь: на основе французской лексики, заимствованной русским и удмуртским языками. - Ижевск: Изд. дом «Удмуртский университет», 2003. - 99 с.

7. Копылова Е.В. Этимология слов интернациональной лексики от классических до современных языков // Наука и современность - 2016: сб. мат. XLII межд. научн.-практ. конф. Новосиб.: Изд-во ЦРНС, 2016. С. 94-100.

8. Уфимцева А.А. Опыт изучения лексики как системы. - М.: Изд-во Академии наук СССР, 1962. - 288 с.

(с) Ильина Юлия Николаевна (julianik23@mail.ru). 